\title{
Macrophage Function During Wallerian Degeneration of Rat Optic Nerve: Clearance of Degenerating Myelin and la Expression
}

\author{
Guido Stoll, ${ }^{1}$ Bruce D. Trapp, ${ }^{1}$ and John W. Griffin ${ }^{1,2}$ \\ Departments of ${ }^{1}$ Neurology and ${ }^{2}$ Neuroscience, The Johns Hopkins University, School of Medicine, Baltimore, Maryland \\ 21205
}

This study examined Wallerian degeneration (WD) of rat optic nerve (ON) with 2 goals: to determine which cell types are involved in myelin degradation and clearance and to evaluate the extent to which la antigen, a product of the immune response genes, is expressed. We examined immunostained $1-\mu \mathrm{m}$ and ultrathin cryosections of rat $\mathrm{ON}$ at 1 , 8, and 16 weeks after nerve transection. Serial $1-\mu \mathrm{m}$ cryosections were stained with monoclonal antibodies to rat la antigen $(0 \times 6)$ and with antibodies that identify astrocytes (GFAP) and monocytes/macrophages (ED1). In normal ON, ED1-positive cells were not found. A few ED1-positive monocytes/macrophages were present in the transected ON at one week. Macrophages were prominent throughout the ON at 8 weeks; by 16 weeks their number was decreasing. These cells contained myelin debris in various stages of digestion. GFAP-positive astrocytes did not contain myelin debris in their cytoplasm.

At all 3 times a subpopulation of the ED1-positive monocytes/macrophages expressed la antigen. la antigen was not detected in endothelial cells or GFAP-positive astrocytes. In ultrathin cryosections stained by immunogold procedures, la immunoreactivity was found exclusively in cells containing multiple vacuoles and myelin debris and lacking intermediate filaments. The same cell type was labeled by ED1 antibodies.

Our results indicate that macrophages remove the vast majority of debris during Wallerian degeneration in the CNS; a proportion of these macrophages concomitantly express la antigen. These results suggest that the la expression by macrophages observed in other CNS disorders does not necessarily reflect specific local immune events, but in some instances can represent a nonspecific response to CNS damage.

This study examined Wallerian degeneration (WD) in rat optic nerve (ON) to investigate which cells are involved in phagocytosis and removal of myelin debris and to determine to what extent Ia antigen, a product of the immune response genes, might

\footnotetext{
Received June 27, 1988; revised Nov. 23, 1988; accepted Dec. 16, 1988.

This work was supported by USPHS-NIH grant PO1 22849 and by grant JF 2030A-1 from the National Multiple Sclerosis Society. G.S. is a postdoctoral fellow supported by the Deutsche Forschungsgemeinschaft (Sto 162/3-1). B.D.T. is Harry Weaver Neuroscience Scholar of the National Multiple Sclerosis Society. We wish to thank Cindy Cootauco for excellent technical assistance, Dr. Diane Griffn for helpful discussions, Dr. C. D. Dijkstra for supply of EDl antibodies, and Rod Graham for preparing the manuscript.

Correspondence should be addressed to Dr. Stoll at his present address: Neurologische Klinik der Universität Duesseldorf, Moorenstr. 5, D-4000 Duesseldorf, Federal Republic of Germany.

Copyright (C) 1989 Society for Neuroscience $0270-6474 / 89 / 072327-09 \$ 02.00 / 0$
}

be expressed. The first of these issues, the origin and nature of phagocytic cells in the CNS, has a long history of controversy (see Ramón y Cajal, 1913, for a historical review). Based on cytological criteria, both oligodendrocytes and astrocytes have bccn reportcd to be rcsponsiblc for myclin removal during WD in the CNS (Ferraro and Davidoff, 1928; Lampert and Cressman, 1966; Cook and Wisnewski, 1973). In contrast, other groups have shown that macrophages infiltrate the transected optic nerve (Perry et al., 1987) and engulf or phagocytose myelin (Bignami and Ralston, 1969); the latter report found no evidence that oligodendrocytes or astrocytes participate in phagocytosis of myelin. These discrepant findings may be due in part to the difficulty in identifying these cell types based only on morphological criteria. We examined $1-\mu \mathrm{m}$ and ultrathin cryosections of rat $\mathrm{ON}$ at 1,8 , and 16 weeks after transection using monoclonal antibodies to rat monocytes/macrophages (ED1) (Dijkstra et al., 1985), astrocytes (GFAP) (Bignami et al., 1972), and Ia antigen (OX6). We found that cells of monocyte/macrophage lineage appeared in the degenerating $\mathrm{ON}$ and phagocytosed myelin.

The second goal was to determine whether Ia antigen is expressed during WD, a non-immunologically mediated condition. The expression of Ia antigen in nervous system diseases is an active area of investigation; its expression is often taken to connote an immunologically mediated process. Ia antigen, a product of the immune response genes (I-region), is encoded within the major histocompatibility complex (Benacerraf and Germain, 1976; Gill et al., 1983). It plays a crucial role in antigen recognition by most T-cell subsets (Benacerraf and Germain, 1976; Lowy et al., 1984). Almost all tissues contain strategically distributed antigen-presenting cells that can express Ia antigen and play a primary role in the initiation of immune responses (Steinmann and Nussenzweig, 1980; Hirschberg et al., 1982; Streilein and Bergstresser, 1984; Unanue et al., 1984; Hickey and Kimura, 1988). In the normal CNS, Ia antigen is expressed only by rare cells (Wong et al., 1984; Vass et al., 1986). However, $\mathrm{T}$-cell factors like y-interferon can induce Ia expression in vitro by a wide range of cells that are normally Ia negative (Pober et al., 1983; Janeway et al., 1984), including astrocytes (Hirsch et al., 1983; Fontana et al., 1984; Wong et al., 1984). In vivo, Ia expression by glial cells and phagocytes has been shown in a variety of experimental and human inflammatory CNS diseases such as experimental allergic encephalomyelitis (Sobel et al., 1984; Hickey et al., 1985; Matsumoto and Fujiwara, 1986; Vass et al., 1986), virus-induced demyelination (Rodriguez et al., 1987), and multiple sclerosis (Traugott et al., 1985). The significance of Ia expression in these disorders is uncertain; in some of these settings it is likely to reflect specific immune responses, but the possibility of nonspecific Ia expression in nervous system 

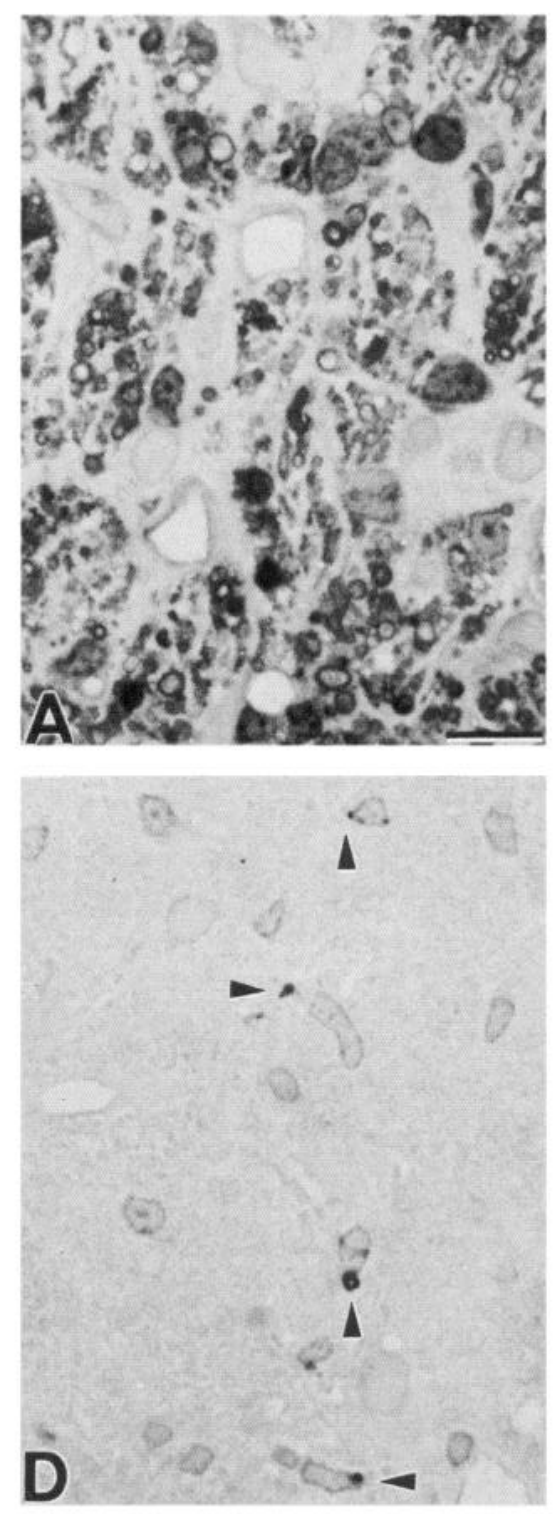
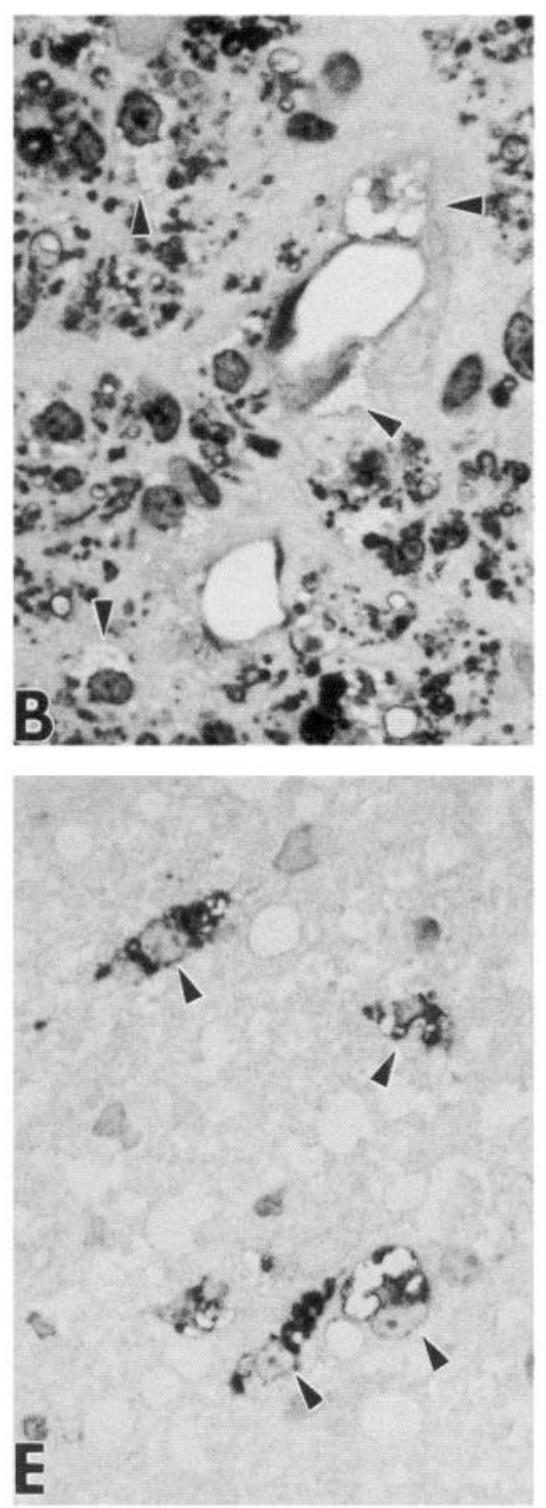
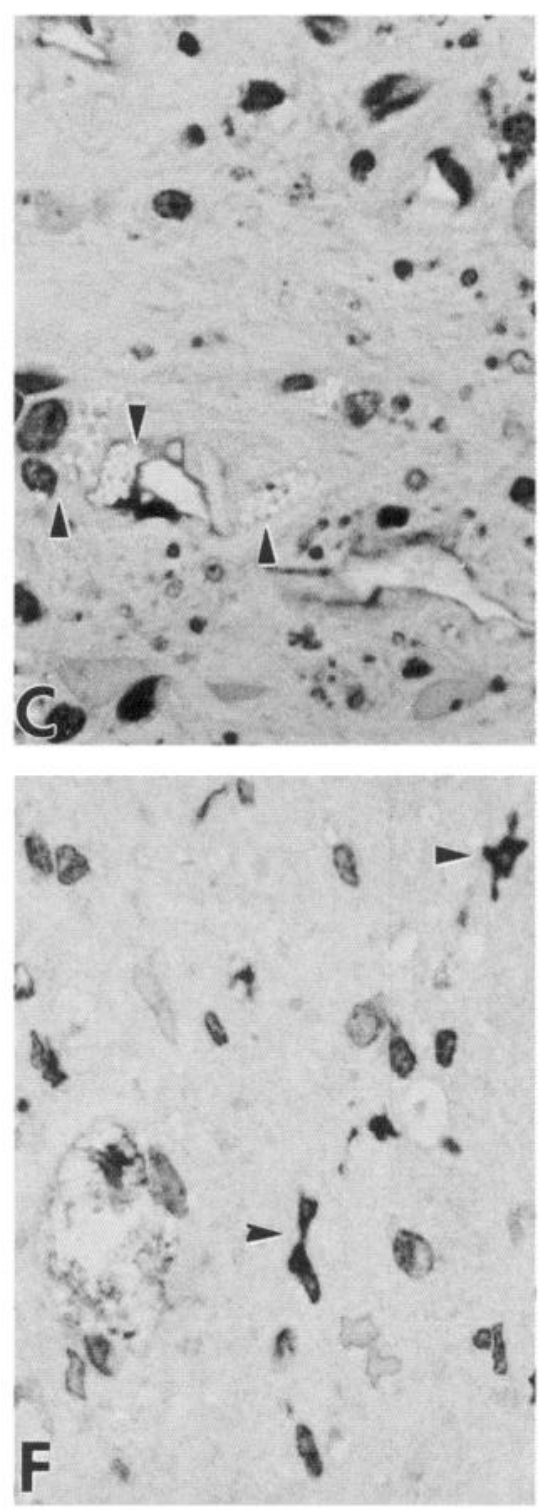
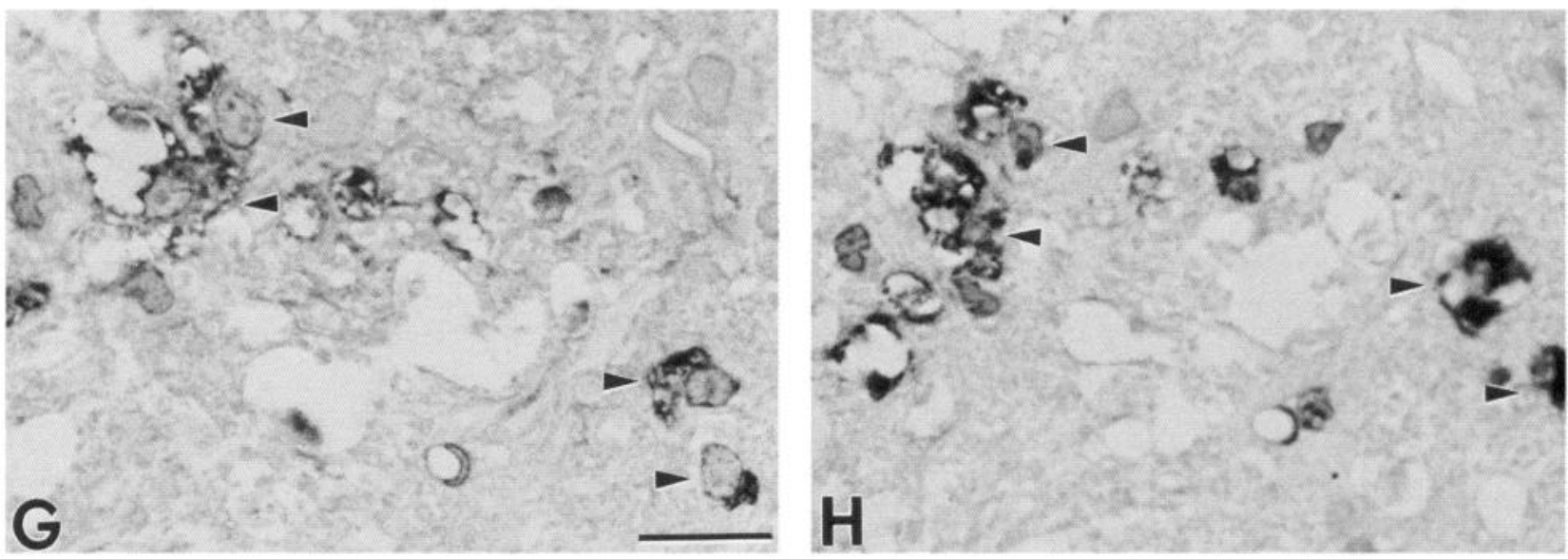

Figure 1. Clearance of myelin and appearance of ED1-positive monocytes/macrophages in WD of rat ON. $A-C$, Semithin plastic sections at 1 , 8 , and 11 weeks after $\mathrm{ON}$ transection. $D-F, 1-\mu \mathrm{m}$ cryosections at corresponding time points of transected $\mathrm{ON}$ at 1,8 , and 16 weeks labeled with monoclonal antibody ED1 $(1: 1000)$ to identify cells of monocytes/macrophage lineage. One week after transection, no phagocytic cells can be identified in plastic sections $(A)$. In the corresponding $1-\mu \mathrm{m}$ section a small number of ED1-positive monocytes/macrophages are present $(D)$; note that ED1 immunoreactivity is restricted to small areas around nuclei, most likely representing small lysosomes (arrowheads). At 8 weeks, the vast majority of myelin debris has not been removed from the degenerating ON $(B)$; cells with multiple vacuoles had appeared (arrowheads). In $1-\mu \mathrm{m}$ 

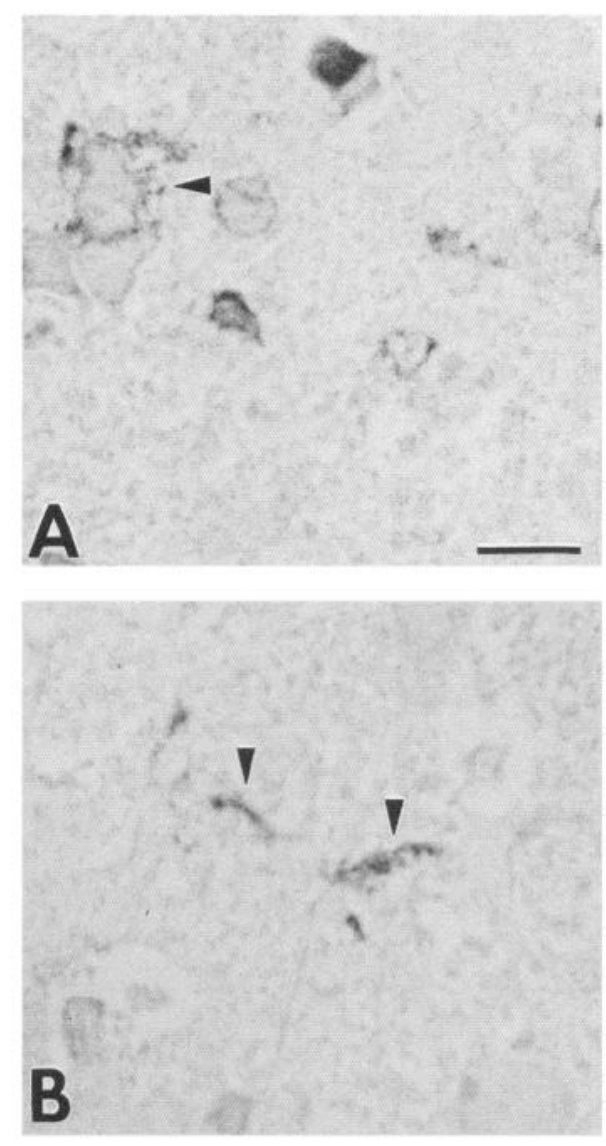
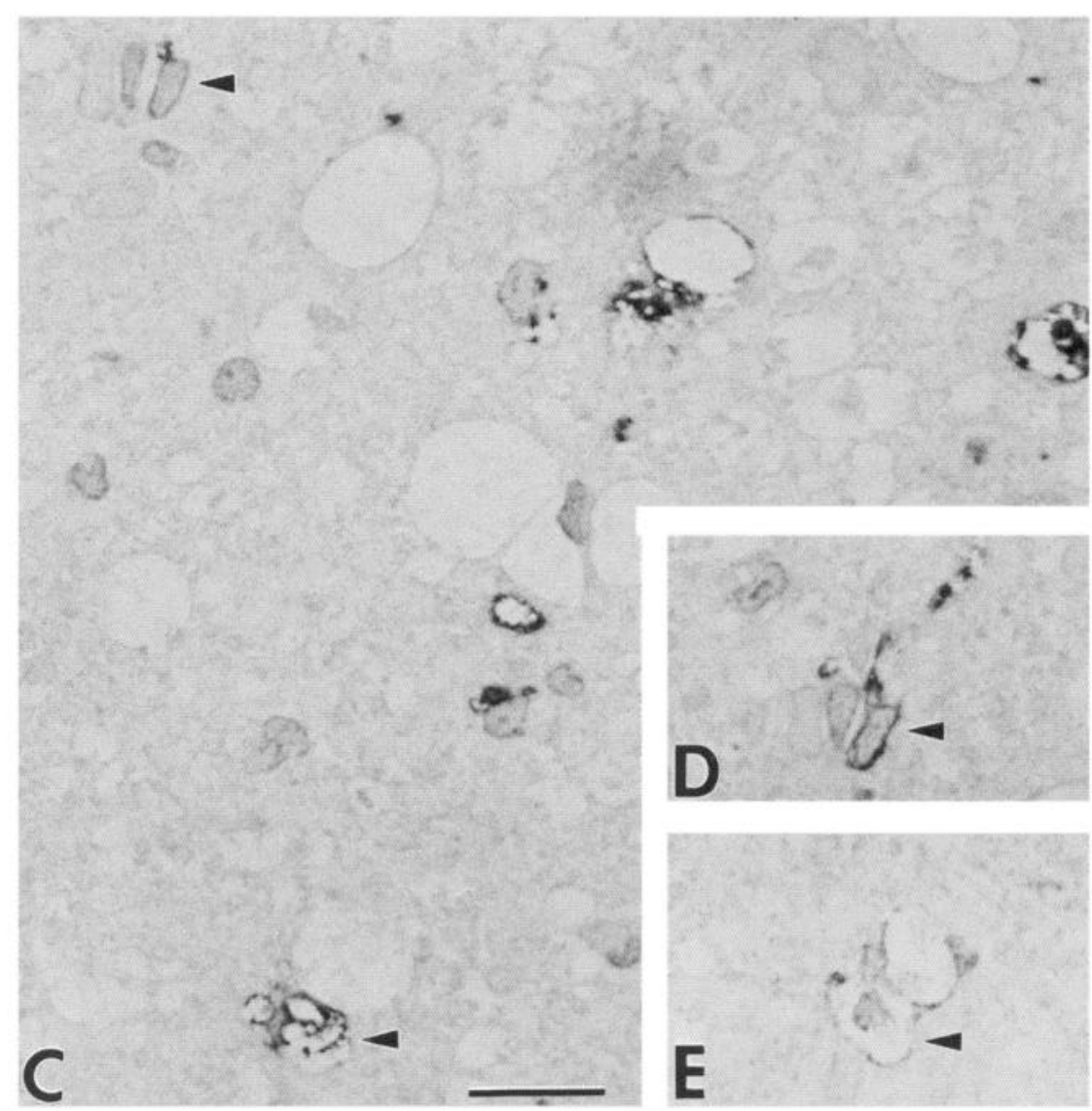

Figure 2. Identification of Ia-positive cells as monocytes/macrophages in WD of rat ON. Transverse $1-\mu \mathrm{m}$ frozen sections of transected ON after 1 week $(A, B)$ and 8 weeks $(C-E)$ labeled with purified anti-Ia antigen antibody Ox6 $(1: 10 ; A, B, D, E)$ and monocyte/macrophage specific monoclonal antibody ED1 $(1: 1000 ; C)$. Early in WD only a few cells express Ia antigen (arrowhead in $A$ ), and mainly processes are labeled $(B)$. Eight weeks after transection, the number of ED1-positive macrophages has increased $(C)$, and a subpopulation of them express Ia immunoreactivity in a subsequent $1-\mu \mathrm{m}$ section. Arrowheads in $D$ and $E$ denote same cells as in C. Scale bars: $10 \mu \mathrm{m}(A, B) ; 20 \mu \mathrm{m}(C-E)$.

diseases has received little attention. In this report we describe the identification and the time course of appearance of Ia-positive cells in WD.

\section{Materials and Methods}

Adult female Lewis rats (6-8 weeks old) were anesthetized, and one ON was transected in the orbit. Groups were fixed by perfusion in phosphatebuffered $4 \%$ paraformaldehyde $0,1,8$, and 16 weeks later. ON of unoperated animals and transected ON were dissected, postfixed in $4 \%$ paraformaldehyde overnight, infiltrated with $1 \mathrm{M}, 2 \mathrm{M}$, and $2.3 \mathrm{M}$ sucrose (the latter containing $30 \%$ polyvinyl pyrrolidone) for $1 \mathrm{~d}$ each, placed on specimen stubs, and frozen in liquid nitrogen. One- $\mu \mathrm{m}$ serial frozen sections were cut according to established procedures (Tokuyasu, 1980; Griffiths et al., 1983) in a Reichert Ultracut/FC-4 ultramicrotome maintained at approximately $-90^{\circ} \mathrm{C}$. Sections were transferred after thawing to polylysine-coated slides in loops containing $1 \mathrm{~m}$ sucrose. Sections were stained by the avidin-biotin-peroxidase complex technique (Hsu et al., 1981) using purified monoclonal IgG to Ia antigen (Ox6 1:10; Seralab, UK) and the following antibodies to define cell types: mouse monoclonal anti-GFAP (1:1000; Boehringer, FRG) for astrocytes (Big- nami et al., 1972); mouse monoclonal ED1 antibody for monocytes/ macrophages (1:1000), a gift from C. D. Dijkstra (Dijkstra et al., 1985); and biotinylated isolectin B4 from Griffonia seeds (1:10 of $0.2 \mathrm{mg}$ diluted in $0.5 \mathrm{ml}$ PBS; Sigma), a suggested marker for microglia (Streit and Kreutzberg, 1987).

For electron-microscopical immunocytochemistry, ultrathin cryosections $\left(12 \mathrm{~nm}\right.$ thick) of transected $\mathrm{ON}$ were cut at $-110^{\circ} \mathrm{C}$ (Tokuyasu, 1980; Griffiths et al., 1983) and transferred with loops to formvar- and carbon-coated hexagonal mesh grids. Grids were maintained, sections facing down, on $2 \%$ gelatin in PBS at $4^{\circ} \mathrm{C}$ for $2 \mathrm{hr}$. Grids were processed for immunocytochemistry using an immunogold procedure (Slot and Geuze, 1984) essentially as described (Trapp et al., 1988). Briefly, after incubation in $10 \%$ ovalbumin and $3 \%$ normal goat serum for $30 \mathrm{~min}$, primary antibodies (GFAP 1:100, Ox6 1:2, and ED1 1:1000) were applied at $4^{\circ} \mathrm{C}$ overnight, followed by $2 \mathrm{hr}$ of a $1: 20$ dilution of $15 \mathrm{~nm}$ gold-labeled goat anti-mouse IgG (Janssen Pharmaceutical) and postfixation in $2.5 \%$ glutaraldehyde for $5 \mathrm{~min}$. The sections were then stained with neutral uranyl acetate (10 min), followed by embedding in $1.3 \%$ methylcellulose (Fluka AG, Buchs, Switzerland) containing $0.3 \%$ acidic uranyl acetate (Tokuyasu, 1980). Grids were examined in a Hitachi H-600 electron microscope.

cryosections, ED1-positive cells now contain heavily labeled large vacuoles indicating their phagocytic activity ( $E$, arrowheads). By 11 weeks, most of the myelin debris has been removed, and only a few cells with vacuoles can be found $(C$, arrowheads). Accordingly, only a few ED1-positive monocytes/macrophages are found 16 weeks after transection in 1- $\mu$ m cryosections $(F$, arrowheads). The nuclei of these cells (blue in original slides) are surrounded by darker reaction product, which appears brown in original sections (arrowheads). $G$ and $H$ are serial $1-\mu$ m cryosections 8 weeks after ON transection. Note that identical cells (arrowheads) are labled with ED1 antibodies $(G)$ and isolectin B4 $(H)$. Scale bars: $10 \mu \mathrm{m}(A-F) ; 20$ $\mu \mathrm{m}(G, H)$. 

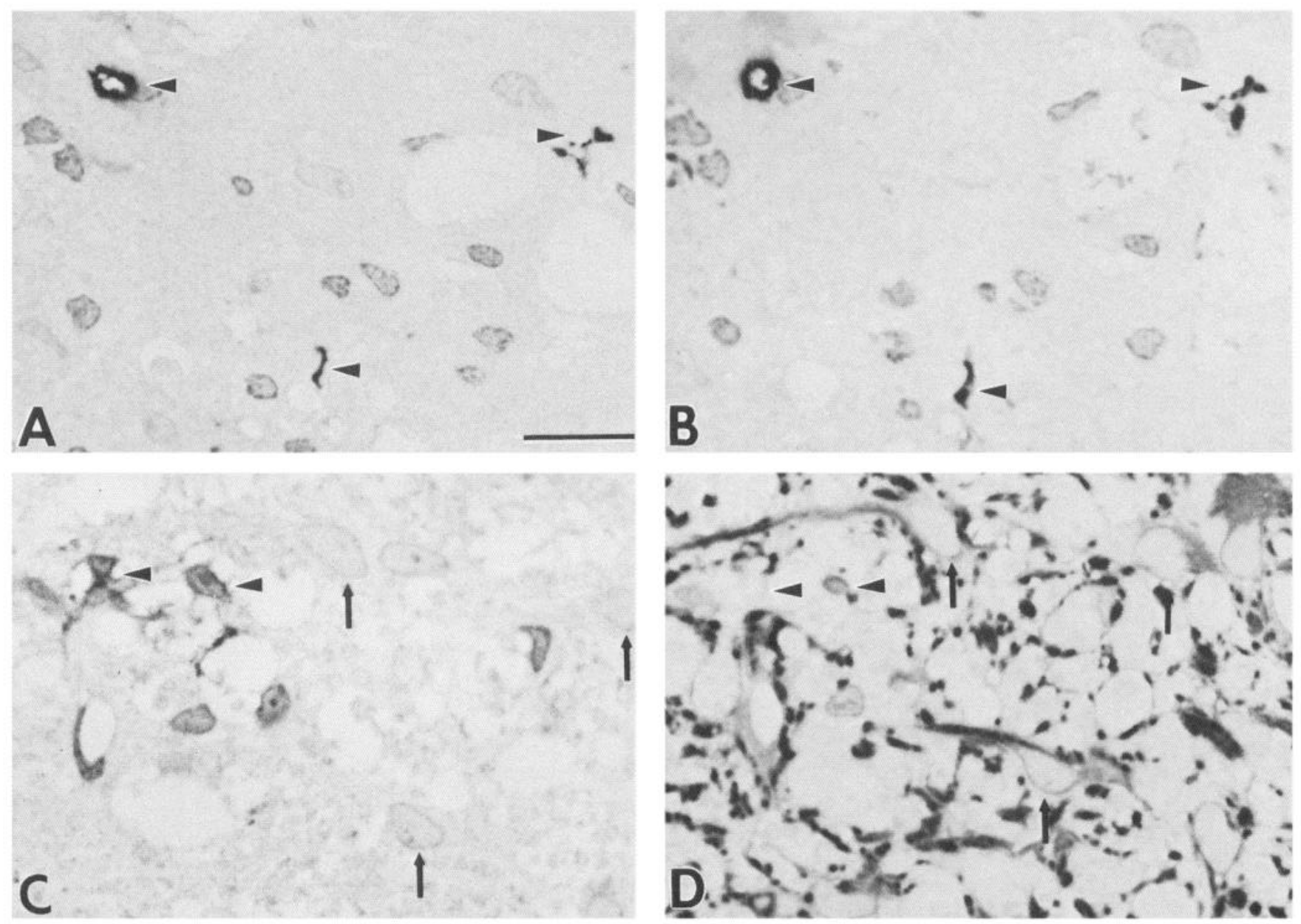

Figure 3. Transverse $1-\mu \mathrm{m}$ frozen sections of transected $\mathrm{ON}$ after 16 weeks $(A, B)$ and 8 weeks $(C, D)$ labeled wtih purified anti-Ia antigen antibody Ox6 $(A, C)$, ED1 $(B)$, and GFAP $(D)$. Sixteen weeks after ON injury, Ia-positive cells are still present $(A)$. They can be identified as ED1-positive monocytes/macrophages in a subsequent section $(B)$. $C$ shows that Ia-positive phagocytes are GFAP-negative in a subsequent $1-\mu \mathrm{m}$ section $(D$, arrowheads). Additionally, GFAP-positive astrocytes in $D$ do not express Ia antigen in $C$ (arrows). Scale bar, $20 \mu \mathrm{m}$.

Additionally, optic nerves of Sprague-Dawley rats were processed for conventional light and electron microscopy 1,8 , and 11 weeks after transection. Specimens were fixed in $3 \%$ glutaraldehyde and $4 \%$ paraformaldehyde, postfixed in $2 \%$ osmium tetroxide in $0.1 \mathrm{~m}$ phosphate buffer, and embedded in Epon resin. Semithin sections were stained with toluidine blue. Thin sections were stained with uranyl acetate and lead citrate and examained in a Hitachi H-600 electron microscope.

\section{Results}

Appearance of phagocytes in $O N W D$

Throughout the course of WD, EDl-positive cells were present, but their appearance and number changed. In 3 normal ON, no ED1-positive cells were seen (data not shown). Seven to $10 \mathrm{~d}$ after ON transection, myelin sheaths often appeared flattened or collapsed and were forming ovoids, but no phagocytic cells with multiple vacuoles could be detected in semithin plastic sections (Fig. 1 $\mathrm{A}$ ). In the corresponding $1-\mu \mathrm{m}$ cryosections, only a small number of ED1-positive monocytes/macrophages could be identified. The ED1 immunoreactivity in these cells was restricted to small areas around the nuclei (Fig. $1 D$ ); at this early stage of WD, these cells did not have the large vacuoles characteristic of phagocytes.

Eight weeks after $\mathrm{ON}$ transection, a large amount of myelin debris in various stages of digestion was still present in the degenerating ON (Fig. 1B). Plastic sections revealed numerous cells with multiple vacuoles scattered throughout the $\mathrm{ON}$, some in close association with blood vessels (Fig. $1 B$ ). In $1-\mu$ m cryosections, the number of ED1-positive monocytes/macrophages had increased markedly, and their appearance had changed. ED1-positive cells now contained large ED1-positive vacuoles, reflecting their phagocytic activity (Fig. $1 E$ ).

By 11 weeks the vast majority of myelin debris had been removed, and the nerve was filled with hypertrophic astrocytic processes. Only occasional cells with vacuoles could be found in plastic sections (Fig. 1C); this corresponded with a marked reduction in the number of ED1-positive cells in 1- $\mu \mathrm{m}$ cryosections at 16 weeks (Fig. $1 F$ ).

To further characterize the nature of the ED1-positive cells in these ONs, we reacted serial $1-\mu \mathrm{m}$ sections with ED1 antibodies and with isolectin B4 from Griffonia seeds, which has been used as a marker for microglia (Streit and Kreutzberg, 1987). The same cells were stained in these serial sections (Fig. $1, G, H)$. As discussed below, we interpret both markers as being capable of identifying cells of monocyte/macrophage lineage, probably including microglia. 

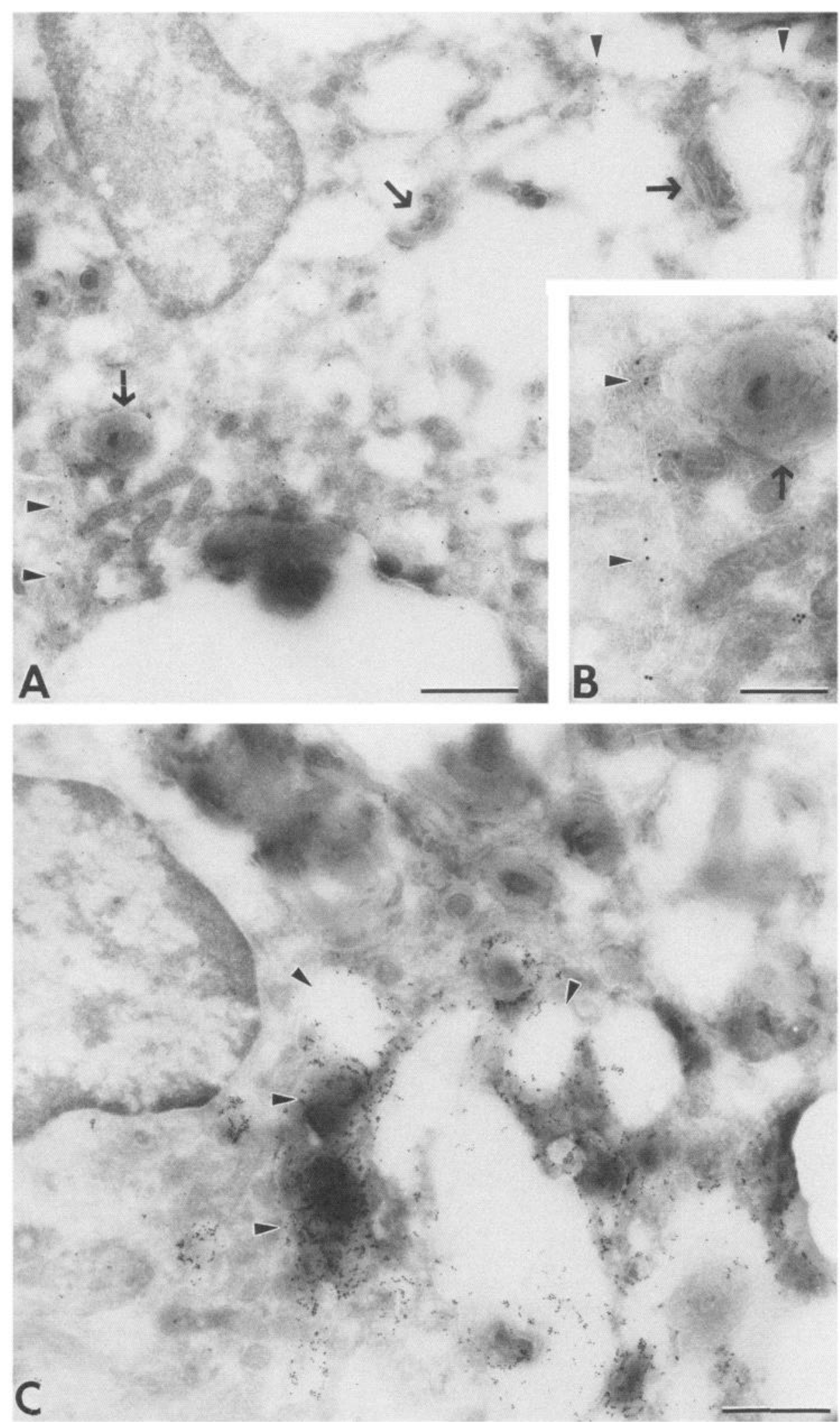

Figure 4. $A, B$, Subcellular localization of Ia antigen (purified Ox6 IgG 1: 2 ) in monocytes/macrophages in thin frozen sections using an immunogold procedure in rat optic nerve 8 weeks after transection. Gold particles are found diffusely in the cytoplasm and presumably on the surface (arrowheads in $A$ and $B$ ) of cells which contain lucent vacuoles and phagocytosed myelin (arrows). Note the absence of intermediate filaments. $C$, Virtually the same cell type can be labeled with the monoclonal antibody ED1 (1:1000), an established monocyte/macrophage marker. Lamellar structures and areas around lucent vacuoles (arrowheads) are heavily labeled in these phagocytes, while other areas of the cytoplasm are ED1-negative. The relatively large size of vacuoles in phagocytes in thin frozen sections $(A, C)$ compared to that found in conventional EM micrographs of these cells (see Fig. 5) is most likely due to spreading of sections during transfer from cryobox to grids. Scale bars: $1 \mu \mathrm{m}$ $(A, C) ; 0.5 \mu \mathrm{m}(B)$.

\section{Ia expression in transected $O N$}

In 3 normal adult $\mathrm{ON}$, no Ia immunoreactivity was found. At one week after transection, a few Ia-positive cells were seen (Fig.
$2 A)$. Ia immunoreactivity was mainly associated with small processes (Fig. 2B). An unequivocal identification of these Ia-positive cells was not possible at this early stage of WD; we did not find the same cell stained by both Ox6 and ED1 in serial 
Figure 5. Identification of an astrocyte in ultrathin cryosections 8 weeks after $\mathrm{ON}$ transection by labeling with monoclonal antibody to GFAP $(1: 100)$. Gold particles are associated with intermediate filaments. Astrocytic cytoplasm and processes appear to entirely surround myelin debris (arrowheads). Because the obtainable contrast is lower in frozen sections than in plastic embedded material, cell borders often cannot be seen. It remains unclear whether myelin has been phagocytosed by this astrocyte. Scale bar, $0.5 \mu \mathrm{m}$.

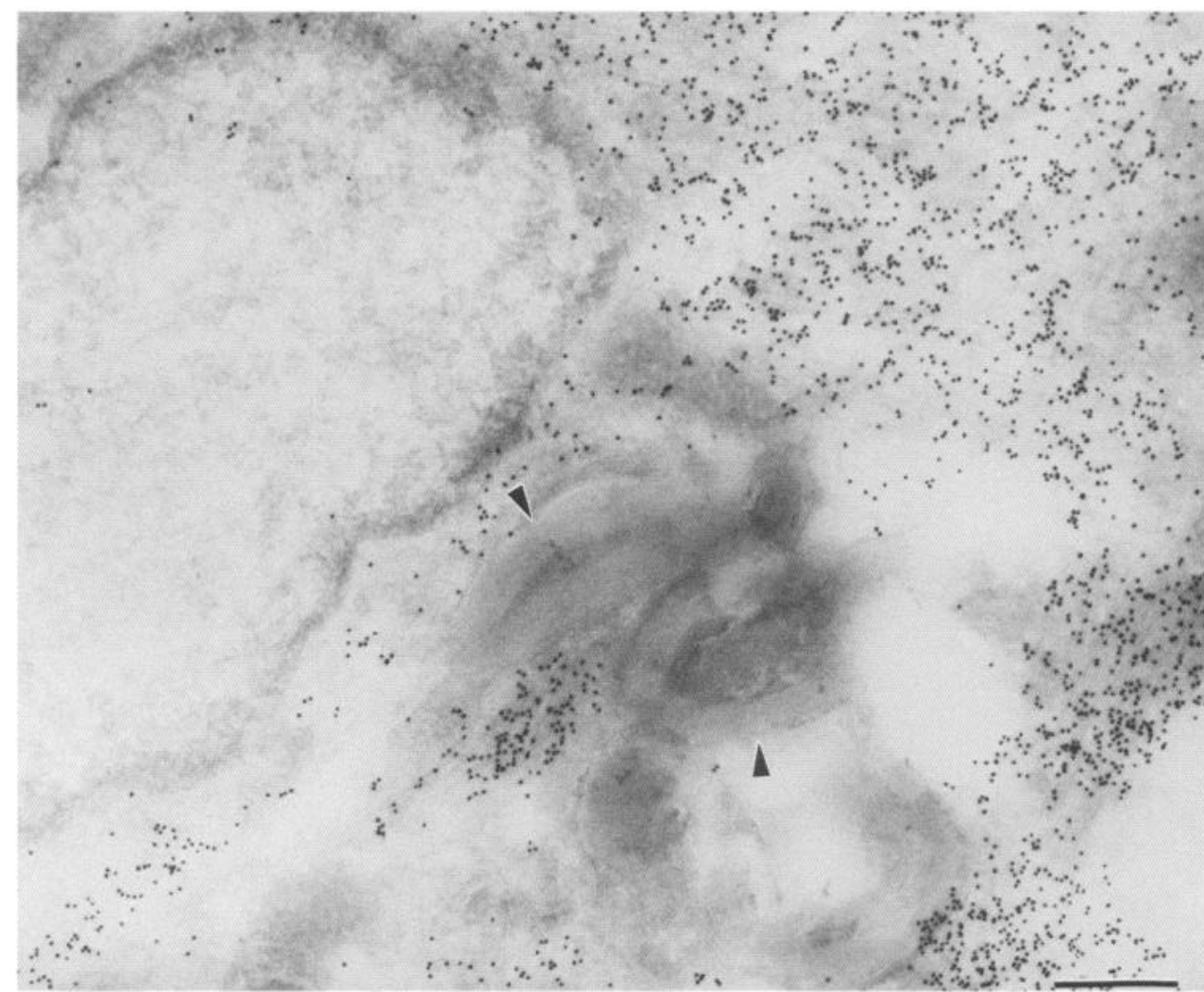

sections, but this probably reflects the differing distributions of the antigens in these prephagocytic cells (ED1 near the nucleus, Ia in the processes).

Eight weeks after ON transection, the number of Ia-positive cells had increased. Staining adjacent $1-\mu \mathrm{m}$ sections with Ox6 antibodies and ED1 revealed that a subpopulation of macrophages expressed Ia antigen (Fig. 2, C-E). About one-third of ED1-positive monocytes/macrophages were Ia positive in a single plane of section. Ia expression was predominantly seen on monocytes/macrophages lacking large vacuoles and exhibiting only small areas of ED1 immunoreactivity; ED1-positive phagocytes in advanced stages of myelin digestion did not express Ia antigen. Ia immunoreactivity was found predominantly on the cell surface on the light microscopical level.

Sixteen weeks after transection, most areas of the ON contained prominent GFAP-positive astrocytic cell bodies and processes. The number of ED1-positive cells had decreased, and concomitantly the number of Ia-expressing cells was lower. Again, the Ia-positive cells were ED1-positive monocytes/macrophages with few vacuoles (Fig. 3, $A, B$ ). Large phagocytes were Ia negative. GFAP-positive astrocytes did not express Ia antigen (Fig. $3, C, D$ ). Ia immunoreactivity associated with endothelial cells was never seen.

\section{Ultrastructural observations}

The identification of Ia-positive cells as monocytes/macrophages was confirmed by immunocytochemistry on ultrathin cryosections 8 weeks after $\mathrm{ON}$ transection. In some cells containing vacuoles and myelin debris, gold particles indicating Ia immunoreactivity were seen on or near the plasma membrane as well as scattered diffusely within the cytoplasm (Fig. 4, $A, B$ ).
The ultrastructural morphology of these Ia-positive cells was identical to monocytes/macrophages exhibiting ED1 immunoreactivity (Fig. 4C). EDl immunoreactivity was restricted to areas of vacuoles and lamellar structures in these phagocytes, while other parts of the macrophage cytoplasm were unstained (Fig. 4C). Astrocytes, identified by the presence of GFAP-positive intermediate filaments (Fig. 5), were Ia negative.

The intracellular distribution of myelin debris was also examined in conventional ultrathin sections. As noted above, a large amount of myelin and myelin debris was still present 8 weeks after $\mathrm{ON}$ transection. Phagocytosed myelin debris could be found in the cytoplasm of cells; these cells often contained lipid droplets and cholesterol crystals, reflecting digestion of myelin (Fig. 6A). The morphology of these cells undoubtedly corresponded to the ED1/Ia-positive cells found in ultrathin cryosections (Fig. 4, $A, C$ ). Cells involved in phagocytosis and breakdown of myelin never contained the bundles of intermediate filaments or junctional complexes (desmosomes or tight junctions) characteristic of astrocytes. Processes of astrocytes frequently were near degenerating myelin (Fig. $6 \mathrm{~B}$ ). The cell borders between these processes and degenerating myelin could often, but not always, be seen. It cannot be excluded that a small amount of myelin was phagocytosed by astrocytes, but we never found myelin debris in the enlarged astrocytic cell bodies, identified by the presence of intermediate filaments, that covered large areas of the degenerating ON (Fig. 6B).

\section{Discussion}

The major findings of this study are that the cells involved in myelin phagocytosis and digestion during WD in the rat ON are monocytes/macrophages and that a proportion of these 

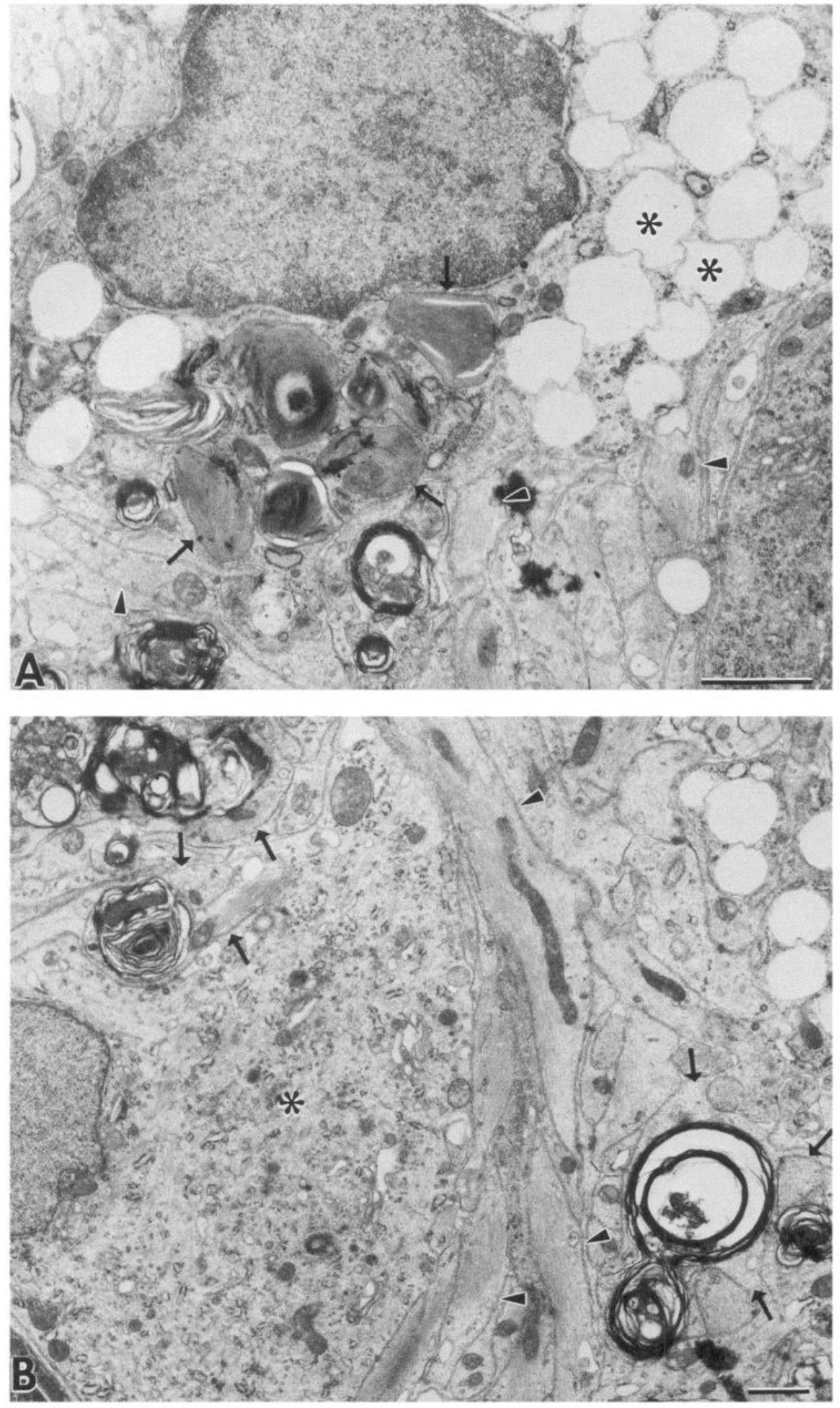

Figure 6. Ultrastructural morphology of macrophages and astrocytes in ultrathin sections of plastic embedded ON 8 weeks after transection. $A$, Typical phagocyte containing lipid droplets (as terisks), myelin debris, and myelin degradation products (arrow). Note the absence of intermediate filaments in the cytoplasm of this macrophage, which is surrounded by many astrocytic processes (arrowheads). B, Cytoplasm of an astrocyte (asterisk) and longitudinally cut astrocytic processes (arrowheads). Arrows denote small astrocytic processes in close association with myelin, some of which are clearly separated from the myelin by membranes; in others, no cell border can be defined. Scale bars, $1 \mu \mathrm{m}$. monocytes/macrophages express Ia antigen. Both findings were based on immunocytochemical identification of cells by labeling $1-\mu \mathrm{m}$ and ultrathin cryosections with established marker antibodies: GFAP for astrocytes (Bignami et al., 1972) and ED1 for monocytes/macrophages (Djikstra et al., 1985). The specificity of the ED1 antibodies for cells of the monocyte/macrophage lineage has previously been demonstrated based on correlation with immunoreactivity in lymphoid organs and cell suspensions 
combined with established methods of identifying macrophages such as phagocytosis of latex particles and acid phosphatase activity (Dijkstra et al., 1985). This antibody has been used to localize infiltrating macrophages during WD in sciatic nerve (Stoll and Mueller, 1986).

Comparison of morphological criteria with immunological staining in ultrathin cryosections revealed that staining patterns in the transected $O N$ were distinctive and highly specific. After the first week, ED1 immunoreactivity was found predominantly in cells having multiple vacuoles and lacking intermediate filaments. The restriction of ED1 labeling to vacuoles and lamellar structures in these monocytes/macrophages suggests that the antigen recognized by the ED1 antibody might be a lysosomal enzyme or protein. GFAP immunoreactivity was found only in cell bodies and processes containing intermediate filaments, an established criterion for the identification of astrocytes in plastic ultrathin sections.

\section{Phagocytosis in WD}

Macrophages seem to be responsible for the removal of most of the myelin debris in this form of CNS injury. The infiltration of the transected ON by ED1-positive monocytes/macrophages corresponded with the time course of myelin degradation and the appearance of mononuclear cells, as described in the ultrastructural study of Bignami and Ralston (1969). Using immunocytochemical staining of ultrathin cryosections, we found that myelin debris was found predominantly in ED1-positive phagocytes. GFAP-positive astrocytes did not appear to participate in the phagocytosis of degenerating myelin.

Degenerating myelin cleared much more slowly in the CNS than it did during WD in the PNS; in the CNS a considerable amount of myelin had not been removed by 8 weeks, and phagocytes were still present 16 weeks after $\mathrm{ON}$ transection. Concomitantly, the recruitment of macrophages in the degencrating $O N$ was much prolonged in comparison to the rapid infiltration of macropahges in the transected sciatic nerve (Stoll and Mueller, 1986; Perry et al., 1987). The reasons for these different responses of monocytes/macrophages in the CNS and PNS are unclear.

To what extent activated resident microglia might contribute to the population of ED1-positive cells is unknown. The nature of microglia has been a long-standing matter of controversy. Del Rio Hortega proposed that the microglia were of mesodermal origin (del Rio Hortega, 1932). Some authors have argued that microglia are derived from blood monocytes (Ling, 1981; Murabe and Sano, 1982), and others that microglia are of neuroectodermal origin (Fujita and Kitamura, 1976; Oehmichen, 1982). Recently, it has been shown unequivocally that microglial cells are bone marrow derived (Hickey and Kimura, 1988). Isolectin B4 from Griffonia seeds has been used as a marker for microglial cells (Streit and Kreutzberg, 1987), but we found that the same cells were identified by both markers. Moreover, a small proportion of spleen cells can be stained with this lectin (W. Tyor, personal communication). Using the monoclonal antibody F4/80 to mouse macrophages, Perry and colleagues (1985) reported similar observations in mouse brain. Macrophages and microglia in the developing and adult mouse brain could not be distinguished by labeling with the F4/80 antibody and monoclonal antibodies against the $\mathrm{Fc}$ and $\mathrm{C} 3$ receptors usually found on macrophages. In conclusion, we think that ED1-positive phagocytes found in ON WD include monocytes/macrophages of hematogenous origin as well as microglia.

\section{Ia expression in WD}

There are several explanations for Ia expression by monocytes/ macrophages in WD: (1) The number of Ia-positive monocytes/ macrophages may simply reflect the proportion of Ia-positive cells in the circulation; this seems unlikely because the number of Ia-positive cells in WD exceeds the proportion of monocytes in the circulation normally expressing Ia (Beller and Unanue, 1981); (2) monocytes/macrophages may become Ia-positive when entering the degenerating nerves; and (3) Ia-positive monocytes/ macrophages can be selectively recruited. Because Ia-positive cells in WD of the PNS are concentrated around vessels (G. Stoll, unpublished observations) and often have the morphological features of monocytes with only focal sites of ED1 immunoreactivity, we favor the third possibility, that activated monocytes/macrophages preferentially infiltrate degenerating nerves. Many phagocytic macrophages containing myelin debris in advanced stages of digestion were Ia negative. This may be due to the lack of stimulating factors like y-interferon in transected nerves; such factors are known to be necessary to maintain Ia expression by macrophages in culture (Beller and Unanue, 1981).

Astrocytes and endothelial cells did not express detectable amounts of Ia antigen in WD. The expression of Ia antigen by monocytes/macrophages in WD suggests that Ia expression by these cells in inflammatory CNS diseases is not necessarily a specific consequence of immune mechanisms, but may represent a response to CNS damage. This could apply, at least in part, to diseases such as experimental allergic encephalomyelitis, an autoimmune CNS disease mediated by MBP-reactive T-cell lines (Ben Nun et al., 1981) in which Ia antigen has been found predominantly in macrophages and lymphocytes (Masumoto and Fujiwara, 1986; Vass et al., 1986).

\section{References}

Beller, D. I., and E. R. Unanue (1981) Regulation of macrophage populations: II. Synthesis and expression of Ia antigens by peritoneal exudate macrophages is a transient event. J. Immunol. 126:263-269.

Benacerraf, B., and R. N. Germain (1976) The immune response genes of the major histocompatibility complex. Immunol. Rev. 38: 70-119.

Ben Nun, A., H. Wekerle, and I. R. Cohen (1981) The rapid isolation of clonable antigen specific T-lymphocyte lines capable of mediating autoimmune encephalomyelitis. Eur. J. Immunol. 11: 195-199.

Bignami, A., and H. J. Ralston (1969) The cellular reaction of Wallerian degeneration in the central nervous system of the cat. Brain Res. 13: 444-461.

Bignami, A., L. F. Eng, D. Dahl, and C. T. Uyeda (1972) Localisation of the glial fibrillar acidic protein in astrocytes by immunotluorescence. Brain Res. 43: 429-435.

Cook, R. D., and H. W. Wisnewski (1973) The role of oligodendroglia and astroglia in Wallerian degeneration of the optic nerve. Brain Res. 61: $191-206$.

del Rio Hortega, P. (1932) Microglia. In Cytology and Cellular Pathology of the Nervous System, W. Penfield, ed., pp. 482-534, Hoeber, New York.

Dijkstra, C. D., E. A. Doepp, P. Joling, and G. Kraal (1985) The heterogeneity of mononuclear phagocytes in lymphoid organs: Distinct macrophage subpopulations in the rat recognized by monoclonal antibodies ED1, ED2 and ED3. Immunology 54: 589-599.

Ferraro, A., and L. M. Davidoff (1928) The reaction of the oligodendroglia to injury of the brain. Arch. Pathol. 6: 1030-1053.

Fontana, A., W. Fierz, and H. Wekerle (1984) Astrocytes present myelin basic protein to encephalitogenic T cell lines. Nature 307: 273-276.

Fujita, S., and T. Kitamura (1976) Origin of brain macrophages and the nature of microglia. In Progress in Neuropathology, Vol. 3, H. M. Zimmermann, ed., pp. 1-50, Grune and Stratton, London.

Gill, T. J., D. V. Cramer, H. W. Kunz, and D. N. Mistra (1983) 
Structure and function of the major histocompatibility complex of rat. J. Immunogenetics 10:261-273.

Griffiths, G., K. Simons, G. Waren, and K. T. Tokuyasu (1983) Immunoelectron microscopy using thin, frozen sections: Applications to studies of intracellular transport of semiliki Forest virus spike glycoproteins. In Methods in Enzymology, Vol. 96, S. Fleischer and B. Fleischer, eds., pp. 466-485, Academic, New York.

Hickey, W. F., and H. Kimura (1988) Perivascular microglial cells of the CNS are bone marrow-derived and present antigen in vivo. Science 239: 290-292.

Hickey, W. F., J. B. Osborn, and W. M. Kirby (1985) Expression of Ia molecules by astrocytes during acute experimental allergic encephalomyelitis in the Lewis rat. Cell Immunol. 91: 528-535.

Hirsch, M. R., J. Wietzerbin, M. Pierres, and C. Goridis (1983) Expression of Ia antigen by cultured astrocytes treated with gamma-interferon. Neurosci. Lett. 41: 199-204.

Hirschberg, H., L. R. Braathen, and E. Thorsby (1982) Antigen presentation by vascular endothelial cells and epidermal Langerhans cells: The role of HLA-DR. Immunol. Rev. 66: 57-77.

Hsu, S. M., L. Raine, and H. Fanger (1981) The use of avidin-biotinperoxidase complex $(\mathrm{ABC})$ in immunoperoxidase techniques - a comparison between $\mathrm{ABC}$ and the unlabeled antibody (PAP) procedures. J. Histochem. Cytochem. 29: 577-580.

Janeway, C. A., K. Bottomly, J. Babich, P. Conrad, L. McVay, D. B. Murphy, and J. Tite (1984) Quantitative variation in Ia antigen expression plays a central role in immune regulation. Immunol. Today 5: $99-105$.

Lampert, P. W., and M. R. Cressman (1966) Fine structural changes in myelin sheaths after axonal degeneration in the spinal cord of rats. Am. J. Pathol. 49: 1139-1155.

Ling, E. A. (1981) The origin and nature of microglia. In Advances in Cellular Neurobiology, Vol. 2, S. Fedoroff and L. Hertz, eds., pp. 33 82, Academic, London.

Lowy, A., J. A. Drebin, J. G. Monroe, R. D. Granstein, and M. Greene (1984) Genetically restricted antigen presentation for immunological tolerance and suppression. Nature 308: 373-375.

Matsumoto, Y., and M. Fujiwara (1986) In situ detection of class I and II major histocompatibility complex antigens in the rat central nervous system during experimental allergic encephalomyelitis. $\mathrm{J}$. Neuroimmunol. 12: 265-277.

Murabe, Y., and Y. Sano (1982) Morphological studies on microglia. VI. Postnatal development of microglia. Cell Tissue Res. 225: 469485 .

Oehmichen, M. (1982) Functional properties of microglia. In Recent Advances in Neuropathology Vol. 2, W. T. Smith and J. B. Cananagh, eds., pp. 186-198, Churchill Livingstone, Edinburgh.

Perry, V. H., D. A. Hume, and S. Gordon (1985) Immunohistochemical localisation of macrophages and microglia in the adult and developing mouse brain. Neuroscience 15: 313-326.

Perry, V. H., M. C. Brown, and S. Gordon (1987) The macrophage response to central and peripheral nerve injury: A possible role for macrophages in regeneration. J. Exp. Med. 165: 1218-1223.

Pober, J. S., T. Collins, M. A. Gimbrone, R. S. Cotram, J. D. Gitlin, W. Fiers, C. Clayberger, A. M. Krensky, S. J. Burakoff, and C. S. Reiss (1983) Lymphocytes recognize human vascular endothelial and dermal fibroblast Ia antigens induced by recombinant immune interferon. Nature 305: 726-729.

Ramón y Cajal, S. (1913) Degeneration and regeneration of the white matter. In Degeneration and Regeneration of the Nervous System, Vol. 2. R. M. May, ed., pp. 484-516. Oxford U. P., Oxford.

Rodriguez, M., M. L. Pierce, and E. A. Howie (1987) Immune response gene products (Ia antigens) on glial and endothelial cells in virus induced demyelination. J. Immunol. 138: 3438-3442.

Slot, J. W., and H. J. Geuze (1984) Gold markers for single and double immunolabeling of ultrathin cryosections. In Immunolabeling for Electrontmicroscopy, J. M. Polak and I. M. Varndell, eds., pp. 129142, Elsevier,

Sobel, R. A., B. W. Blandrette, A. K. Bhan, and R. B. Colvin (1984) The immunopathology of experimental allergic encephalomyelitis. II. Endothelial cell Ia increase prior to inflammatory cell infiltration. J. Immunol. 132: 2402-2407.

Steinmann, R. M., and M. C. Nussenzweig (1980) Dendritic cells: Features and functions. Immunol. Rev. 53: 125-147.

Stoll, G., and H. W. Mueller (1986) Macrophages in the peripheral system and astroglia in the central nervous system of rat commonly express apolipoprotein $\mathrm{E}$ during development but differ in their response to injury. Neurosci. Lett. 72: 233-238.

Streilein, J. W., and P. L. Bergstresser (1984) Ia antigens and epidermal Langerhans cells. Transplant 30: 319-323.

Streit, W. J., and G. W. Kreutzberg (1987) Lectin binding by resting and reactive microglia. J. Neurocytol. 10: 249-260.

Tokuyasu, K. T. (1980) Immunocytochemistry on ultrathin frozen sections. Histochem. J. 12: 381-403.

Trapp, B. D., L. Bernier, S. B. Andrews, and D. R. Colman (1988) Cellular and subcellular distribution of 2',3-cyclic nucleotide $3^{\prime}$-phosphodiesterase and its m-RNA in the rat central nervous system. J. Neurochem. 51: 859-868.

Traugott, U.. L. C. Scheinberg, and C. S. Raine (1985) On the presence of Ia-positive endothelial cells and astrocytes in multiple sclerosis lesions and its relevance to antigen presentation. J. Neuroimmunol. 8: $1-14$

Unanue, E. R., D. Beller, C. Liv, and P. M. Allen (1984) Antigen presentation: Comments on its regulation and mechanism. J. Immunol. 132: 1-5.

Vass, K., H. Lassmann, H. Wekerle, and H. M. Wisniewski (1986) The distribution of Ia antigen in the lesions of rat acute experimental allergic encephalomyelitis. Acta Neuropathol. (Berl.) 70: 149-160.

Wong, G. H. W., P. F. Bartlett, I. Clark-Lewis, F. Battye, and J. W. Schrader (1984) Inducible expression of $\mathrm{H}-2$ and la antigens on brain cells. Science 310: 688-691. 